\title{
Improvements in Methyl-Bambus[6]uril Synthesis Yield
}

\author{
Julio C. C. de Carvalho, ${ }^{\oplus a}$ Renato S. Cicolani ${ }^{\circledR a}$ and Grégoire J.-F. Demets ${ }^{\circledR * a}$ \\ ${ }^{a}$ Departamento de Química, Faculdade de Filosofia, Ciências e Letras de Ribeirão Preto, \\ Universidade de São Paulo, Av. Bandeirantes, 3900, 14040-901 Ribeirão Preto-SP, Brazil
}

\begin{abstract}
Bambus $[n]$ uril synthesis may be challenging, and it is frequently achieved with low purity and low yields. We have studied the effect of different anions on the synthesis of bambus[6]uril, especially in terms of yield, exploring template effects driven by anions in the reaction medium. The influence of the anions is evident on such syntheses and $\mathrm{ClO}_{4}{ }^{-}$particularly led to unprecedented synthesis yields. Computational calculations have also been used to elucidate the influence of anions on cyclization process.
\end{abstract}

Keywords: bambusuril, anion-template, caviplexes

\section{Introduction}

Bambus $[n]$ urils $(n=4,6)$ macrocycles are obtained by the condensation of substituted glycolurils (at 2,4positions) and paraformaldehyde in acid medium..$^{1-3}$ The cavity of those macrocycles contains methine hydrogen atoms that can bind anions to form stable caviplexes. Methyl-bambus[6]uril (MeBU[6], see Figure 1) was the first bambusuril to be synthesized ${ }^{4,5}$ and it is gaining interest for its potential in supramolecular chemistry. ${ }^{6-8}$ (a)

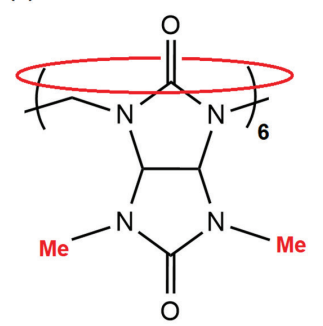

(b)

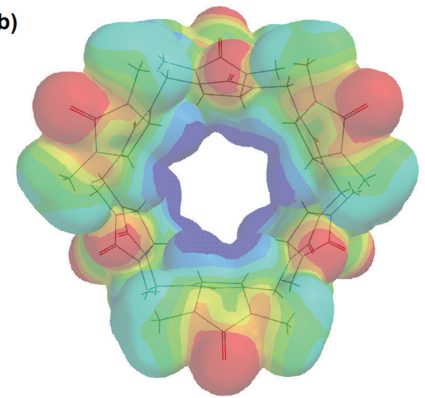

Figure 1. (a) Structural formula of MeBU[6]; (b) top view of MeBU[6] electrostatic potential map, displaying spots with high (red) and low (blue) electron density.

Bambus $[n]$ uril synthesis may be challenging and it is far more sensitive to synthesis parameters than it seems, and it is frequently achieved with high amounts of impurities and, consequently, low yields. As far as we know there are only two procedures described in literature ${ }^{4,9,10}$ to obtain MeBU[6] and, in both of them, chloride ions act

*e-mail: greg@usp.br

Dedicated to Prof Henrique Eisi Toma on the occasion of his $70^{\text {th }}$ birthday. as templates for linear oligomer cyclization. The $24 \mathrm{~h}$ MeBU[6] synthesis, performed in $5.4 \mathrm{~mol} \mathrm{~L}^{-1} \mathrm{HCl}$, leads to yields around $30 \%$, after purification with concentrated $\mathrm{HCl}$ and water. ${ }^{4}$ This fast procedure, however, leads to a series of linear oligomers altogether with MeBU[6] in the final product. Alternatively, the synthesis of MeBU[6] in $9 \mathrm{~mol} \mathrm{~L}^{-1} \mathrm{HCl}$ for seven days $(168 \mathrm{~h}$ ), followed by purification with dimethyl sulfoxide (DMSO) and acetone, yields around $15 \% .9^{9}$ This procedure delivers higher purity MeBU[6], but it is too long. Template species have an important role in cyclization processes since they can induce either thermodynamic or kinetic effect, ${ }^{11,12}$ like it was observed for cucurbit $[n]$ urils and hemi-cucurbit $[n]$ urils. ${ }^{13}$ In the case of MeBU[6], chloride ions are kept inside of the macrocycle's cavity and the synthesis product is always isolated as an anion caviplex, $\mathrm{H}^{+}\left(\mathrm{Cl}^{-} @ \mathrm{MeBU}[6]\right)$ (or $\mathrm{Cl}^{-} @ \mathrm{MeBU}[6]$ to simplify). Anion-free MeBU[6] can be obtained following the procedures described in literature. ${ }^{5,9}$

Theoretical calculations, as well as experimental results, revealed that MeBU[6] can bind several anions, ${ }^{14-16}$ like $\mathrm{Cl}^{-}$, $\mathrm{Br}^{-}, \mathrm{NO}_{3}{ }^{-}$and $\mathrm{ClO}_{4}{ }^{-}$inside its cavity. In the present paper we have used anions of different sizes $\left(\mathrm{Cl}^{-}, \mathrm{Br}^{-}, \mathrm{NO}_{3}^{-}\right.$and $\mathrm{ClO}_{4}^{-}$), in the form of acids, to evaluate their effect on MeBU[6] synthesis yield. We have verified that the nature of the anions is very important for the yields we obtain, especially when using $\mathrm{ClO}_{4}^{-}$.

\section{Experimental}

Fourier transform infrared spectra (FTIR) were recorded in an IR Prestige 21 (Shimadzu) using $\mathrm{KBr}$ pellets. ${ }^{1} \mathrm{H}$ NMR (nuclear magnetic resonance) spectra 
were obtained in a DRX-500 Ultra Shield (Bruker). Mass spectra were obtained in a Xevo TQ-S (Waters), in negative mode $(-2.5 \mathrm{kV})$. Theoretical calculations were made with Wavefunction Spartan 14 software. ${ }^{17}$ The optimized geometries were calculated using the BLYP (Becke-LeeYang-Parr) density functional ${ }^{18}$ and the $6-31 \mathrm{G}^{*}$ basis set (see Supplementary Information (SI) section). ${ }^{19,20}$

The general procedure to obtain MeBU[6] is based on the method described by our group in a previous paper, ${ }^{9}$ however, the syntheses described here were carried out for $48 \mathrm{~h}$ instead of 7 days. In brief, equal amounts of 2,4-dimethylglycoluril ${ }^{10}$ (3.4 mmol), and paraformaldehyde (3.4 mmol, Aldrich, St. Louis, USA) and water were mixed in glass flasks. The suspensions were kept under stirring in a water bath $\left(27^{\circ} \mathrm{C}\right)$ and then different acids $(\mathrm{HCl}, \mathrm{HBr}$, $\mathrm{HNO}_{3}$ or $\mathrm{HClO}_{4}$ ) were slowly added to the mixtures. The flasks were then transferred to a water-containing styrofoam pot $\left(27{ }^{\circ} \mathrm{C}\right)$ and kept under stirring for $48 \mathrm{~h}$. All the syntheses led to white precipitates (MeBU[6] as caviplexes, see SI section) that were collected and purified. Some specific differences may be described for each compound as follows: $\mathrm{H}^{+}\left(\mathrm{Cl}^{-} @ \mathrm{MeBU}[6]\right)$ : water $(0.83 \mathrm{~mL})$ and $37 \%$ $\mathrm{HCl}$ (1.17 mL, Synth, Diadema, Brazil), after stirring time, the mixture was centrifuged and the solid rinsed with water $(2 \mathrm{~mL})$, acetone $(2 \mathrm{~mL}), N, N$-dimethylformamide (DMF)/chloroform (Aldrich; St. Louis, USA) mixture $1: 1 \mathrm{~mol}(2 \mathrm{~mL})$ and acetone $(10 \mathrm{~mL})$. This led to $\mathrm{H}^{+}\left(\mathrm{Cl}^{-} @ \mathrm{MeBU}[6]\right)$ (see Figures S1-S3, SI section) as a white solid. For $\mathrm{H}^{+}\left(\mathrm{Br}^{-} @ \mathrm{MeBU}[6]\right)$ : water $(0.43 \mathrm{~mL})$ and $48 \% \operatorname{HBr}(1.57 \mathrm{~mL}$, Synth, Diadema, Brazil). The solid was washed with $3 \mathrm{~mL}$ of $\mathrm{DMF} / \mathrm{CHCl}_{3}$ mixture 1:1 mol instead of $2 \mathrm{~mL}$. This procedure led to $\mathrm{H}^{+}\left(\mathrm{Br}^{-} @ \mathrm{MeBU}[6]\right)$ (see Figures S4-S6, SI section) as a white solid. For $\mathrm{H}^{+}\left(\mathrm{NO}_{3}{ }^{-} @ \mathrm{MeBU}[6]\right)$ : water $(1.11 \mathrm{~mL})$ and $71 \% \mathrm{HNO}_{3}$ (0.89 mL, Merck, Darmstadt, Germany). This procedure led to $\mathrm{H}^{+}\left(\mathrm{NO}_{3}{ }^{-} @ \mathrm{MeBU}[6]\right)$ (see Figures $\mathrm{S} 7-\mathrm{S} 9$, SI section) as a white solid. For $\mathrm{H}^{+}\left(\mathrm{ClO}_{4}^{-} @ \mathrm{MeBU}[6]\right)$ : water $(0.79 \mathrm{~mL})$ and $70 \% \mathrm{HClO}_{4}(1.21 \mathrm{~mL}$, Sigma-Aldrich, St. Louis, USA). The solid was washed with $3 \mathrm{~mL}$ of $\mathrm{DMF} / \mathrm{CHCl}_{3}$ mixture 1:1 mol instead of $2 \mathrm{~mL}$. This procedure led to $\mathrm{H}^{+}\left(\mathrm{ClO}_{4}{ }^{-} @ \mathrm{MeBU}[6]\right)$ (see Figures $\mathrm{S} 10-\mathrm{S} 12$, SI section) as a white solid. Following this protocol, the acid concentration in all the entries was equal to $7 \mathrm{~mol} \mathrm{~L}^{-1}$.

To exchange included $\mathrm{ClO}_{4}{ }^{-}$for $\mathrm{I}^{-}$ions: $\mathrm{H}^{+}\left(\mathrm{ClO}_{4}^{-} @ \mathrm{MeBU}[6]\right)(0.22 \mathrm{mmol})$ and $55 \%$ hydriodic acid ( $2.00 \mathrm{mmol}$, Merck, Darmstadt, Germany) were solubilized in $12.5 \mathrm{~mL}$ of a chloroform/methanol mixture $(1: 1 \mathrm{v} / \mathrm{v})$ and kept under stirring during one hour. The solvent mixture was then evaporated and the solid was rinsed with water $(2 \times 10 \mathrm{~mL})$ and acetone $(5 \mathrm{~mL})$. This procedure led to $\mathrm{H}^{+}\left(\mathrm{I}^{-} @ \mathrm{MeBU}[6]\right)$ (see Figures S13-S14, SI section) as a white solid. All syntheses were performed at least in duplicate. The same procedure was used to evaluate the reaction time. Several assays under the same conditions described for $\mathrm{ClO}_{4}^{-}$ions were interrupted after 8, 24, 40, 48 and $56 \mathrm{~h}$ under identical conditions. These ones, however, were carried out just once (Figure S15, SI section).

\section{Results and Discussion}

2,4-Dimethylglycoluril cyclization with formaldehyde involves the formation of iminium ions and ammonium intermediaries, both positively charged species. ${ }^{13}$ It is expected for anions, then, to stabilize these species in the form of dimer/trimer ion pairs (see Figure 2). These oligomers favor macrocyclization in detriment of chain polymerization leading to adequate conformations for ring closure: a recurrent process in kinetic template effect that takes place during the formation of several macrocycles. (a)

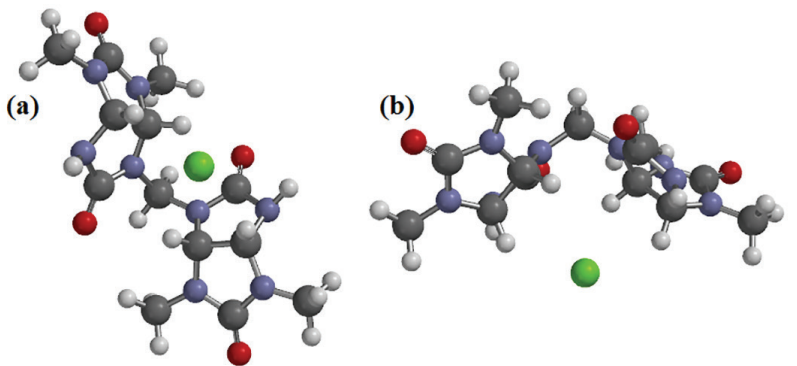

Figure 2. (a) Side and (b) top view of a 2,4-dimethylglycoluril dimer complexed with chloride anion. The gray, red, blue, green and white spheres represent, respectively, carbon, oxygen, nitrogen, chlorine and hydrogen atoms. The structure was calculated from DFT/BLYP 6-31G*.

From Table 1, one can notice that MeBU[6] synthesis yields are directly affected when changing the anion source. Except for $\mathrm{NO}_{3}^{-}$, the yield increases in the following sequence $\mathrm{Cl}^{-}<\mathrm{Br}^{-}<\mathrm{ClO}_{4}^{-}$. Nitric acid is a powerful oxidizing agent and forms large amount of oxidation byproducts rather than MeBU[6], pulling down the yields. ${ }^{21}$ Even displaying concentration-dependent oxidizing properties at room temperature,,$^{22}$ perchlorate ion in acid medium seems to be a better template than nitrate and could be more stabilized by 2,4-dimethylglycoluril units. Due to that, the macrocycle was the major product obtained in the syntheses instead of linear oligomers and other oxidation products. Using perchlorate, the largest anion among the selected ones, we have achieved much higher yields than those reported in literature ${ }^{4,9}$ in periods of time inferior to $48 \mathrm{~h}$.

For a better understanding on how the size of such anions could affect cyclization we have optimized the geometries of $\mathrm{H}^{+}\left(\mathrm{A}^{-} @ \mathrm{MeBU}[6]\right)$, where $\mathrm{A}=\mathrm{Cl}, \mathrm{Br}, \mathrm{NO}_{3}$ or $\mathrm{ClO}_{4}$ (see Figure S16, SI section). According to our 
Table 1. MeBU[6] syntheses yields using different acids $\left(7 \mathrm{~mol} \mathrm{~L}^{-1}\right)$ as source of anions ${ }^{23}$

\begin{tabular}{lcc}
\hline entry & Anion radius ${ }^{23} / \mathrm{pm}$ & Yield / \% \\
\hline $\mathrm{H}^{+}(\mathrm{Cl}-@ \mathrm{MeBU}[6])$ & 181 & $2.9 \pm 0.2$ \\
$\mathrm{H}^{+}\left(\mathrm{Br}^{-} @ \mathrm{MeBU}[6]\right)$ & 196 & $27.2 \pm 2.2$ \\
$\mathrm{H}^{+}\left(\mathrm{NO}_{3}^{-} @ \mathrm{MeBU}[6]\right)$ & 200 & $2.1 \pm 0.1$ \\
$\mathrm{H}^{+}\left(\mathrm{ClO}_{4}^{-} @ \mathrm{MeBU}[6]\right)$ & 240 & $70.0 \pm 4.9$ \\
\hline
\end{tabular}

calculations, both the methylene bridge dihedral angles and cavity internal diameter values for MeBU[6] increase as the anion size increases (see Table 2). From the average methylene bridge dihedral angles (see Figure 3), we can measure the cycle tension at some extent for all the caviplexes. In spite of serving effectively as a template, $\mathrm{Cl}^{-}, \mathrm{Br}^{-}$, and $\mathrm{NO}_{3}^{-}$ions are relatively small and they distribute their charge in smaller volumes, leading to higher macrocyclic ring tension. Conversely, $\mathrm{ClO}_{4}^{-}$ion is relatively

Table 2. Theoretical values for MeBU[6] cavity diameter and methylene bridge dihedral angle obtained by computational calculations. The cavity filling was calculated by dividing the anion volume by the cavity volume, considering both cavity and anion as spheres

\begin{tabular}{lccc}
\hline entry & $\begin{array}{c}\text { Cavity } \\
\text { diameter / } \\
\text { pm }\end{array}$ & $\begin{array}{c}\text { Dihedral } \\
\text { angle / } \\
\text { degree }\end{array}$ & $\begin{array}{c}\text { Cavity } \\
\text { filling / } \\
\%\end{array}$ \\
\hline $\mathrm{H}^{+}\left(\mathrm{Cl}{ }^{-} @ \mathrm{MeBU}[6]\right)$ & 768 & 115.09 & 10.4 \\
$\mathrm{H}^{+}\left(\mathrm{Br}{ }^{-} @ \mathrm{MeBU}[6]\right)$ & 780 & 115.45 & 12.7 \\
$\mathrm{H}^{+}\left(\mathrm{NO}_{3}^{-} @ \mathrm{MeBU}[6]\right)$ & 793 & 115.54 & 12.8 \\
$\mathrm{H}^{+}\left(\mathrm{ClO}_{4}^{-} @ \mathrm{MeBU}[6]\right)$ & 820 & 116.43 & 20.0 \\
\hline
\end{tabular}

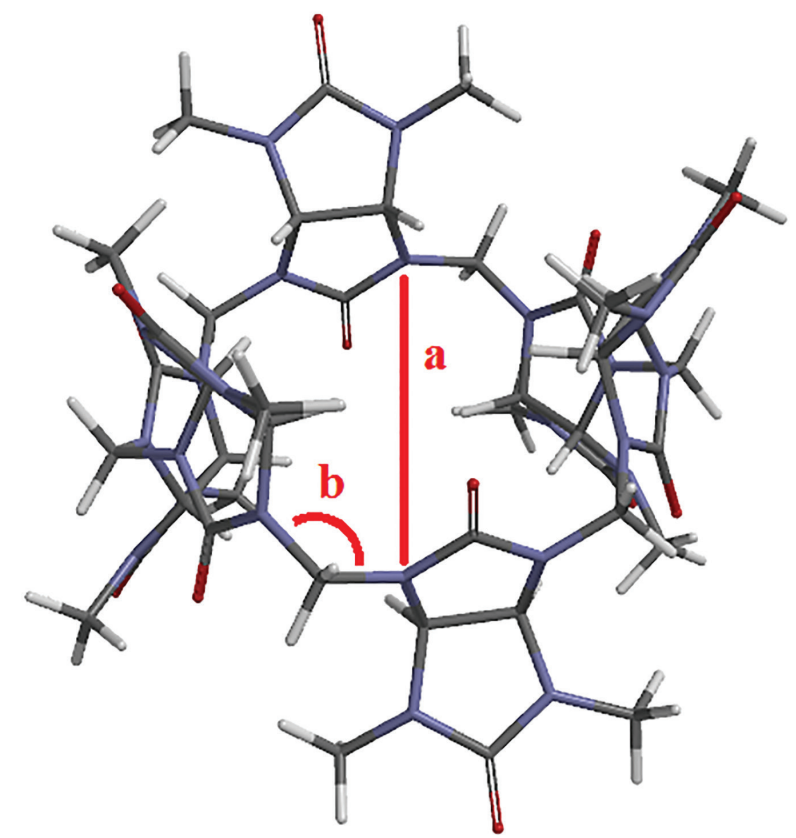

Figure 3. (a) Cavity diameter and (b) methylene bridge dihedral angle for MeBU[6] used in calculations. big and the effects are opposite. Therefore, $\mathrm{ClO}_{4}{ }^{-}$enhances the cyclization process by reducing the macrocycle strain and consequently improves the synthesis yield. This is directly related to Mecozzi-Rebek cavity filling theory and packing coefficient. ${ }^{24}$

Furthermore, the product, in our case MeBU[6], forms very stable complexes with anions, and their solubility is reduced in water, shifting the equilibria towards product formation. It is not trivial to identify which template effect prevails (thermodynamic or kinetic), but we can observe both in these syntheses. Since all of our products (anionincluded MeBU[6]) are not soluble in water, we have assumed that thermodynamic template effect intensity is pretty similar for all entries. In this sense, the impact of anion selection on synthesis yields should be explained preferentially in terms of kinetic effect.

Perchloric acid may be a powerful oxidizer just as strong as or even stronger than $\mathrm{HNO}_{3}$, it depends essentially on its concentration. As we could verify with nitric acid, oxidizing species impair good synthesis yields. We have evaluated how perchloric acid concentration would affect our syntheses. In a first moment (Table 3), increasing concentrations of $\mathrm{HClO}_{4}$ from 3 to $7 \mathrm{~mol} \mathrm{~L}^{-1}$ boost the syntheses yields up to $70 \%$. However, the reactions carried out in more concentrated perchloric acid (from 9 to $11.7 \mathrm{~mol} \mathrm{~L}^{-1}$ ) led to smaller syntheses yields. These results suggest that the perchloric acid in concentrations close to $70 \% \mathrm{~m} / \mathrm{m}$ (i.e., $11.7 \mathrm{~mol} \mathrm{~L}^{-1}$ ) may oxidize the organic compounds and reduce drastically the synthesis yield. ${ }^{22}$ Besides this, $7 \mathrm{~mol} \mathrm{~L}^{-1} \mathrm{ClO}_{4}{ }^{-}$synthesis is very fast. After $24 \mathrm{~h}$ yields around 68\% were verified (Figure S15, SI section).

Table 3. Yield of MeBU[6] synthesis (two days) using perchloric acid in different concentrations

\begin{tabular}{lc}
\hline Acid concentration / $\left(\mathrm{mol} \mathrm{L}^{-1}\right)$ & Yield / \% \\
\hline 3 & 0 \\
5 & $21.5 \pm 1.6$ \\
7 & $70.0 \pm 4.9$ \\
9 & $61.9 \pm 1.7$ \\
11.7 & $45.5 \pm 1.8$ \\
\hline
\end{tabular}

Like the other anions, $\mathrm{ClO}_{4}{ }^{-}$is not easily removed from MeBU[6] cavity simply by precipitation or washing. We managed to exchange $\mathrm{ClO}_{4}^{-}$ions for $\mathrm{I}^{-}$by adding hydriodic acid (in excess) and $\mathrm{H}^{+}\left(\mathrm{ClO}_{4}{ }^{-} @ \mathrm{MeBU}[6]\right)$ in a chloroform/ methanol mixture $(1: 1 \mathrm{v} / \mathrm{v})$. The $\mathrm{ClO}_{4}^{-}$ions oxidize $\mathrm{I}^{-}$ions into iodine according to equation $1 .{ }^{25}$

$\mathrm{ClO}_{4}^{-}+8 \mathrm{I}^{-}+8 \mathrm{H}^{+} \rightarrow \mathrm{Cl}^{-}+4 \mathrm{I}_{2}+4 \mathrm{H}_{2} \mathrm{O}$ 


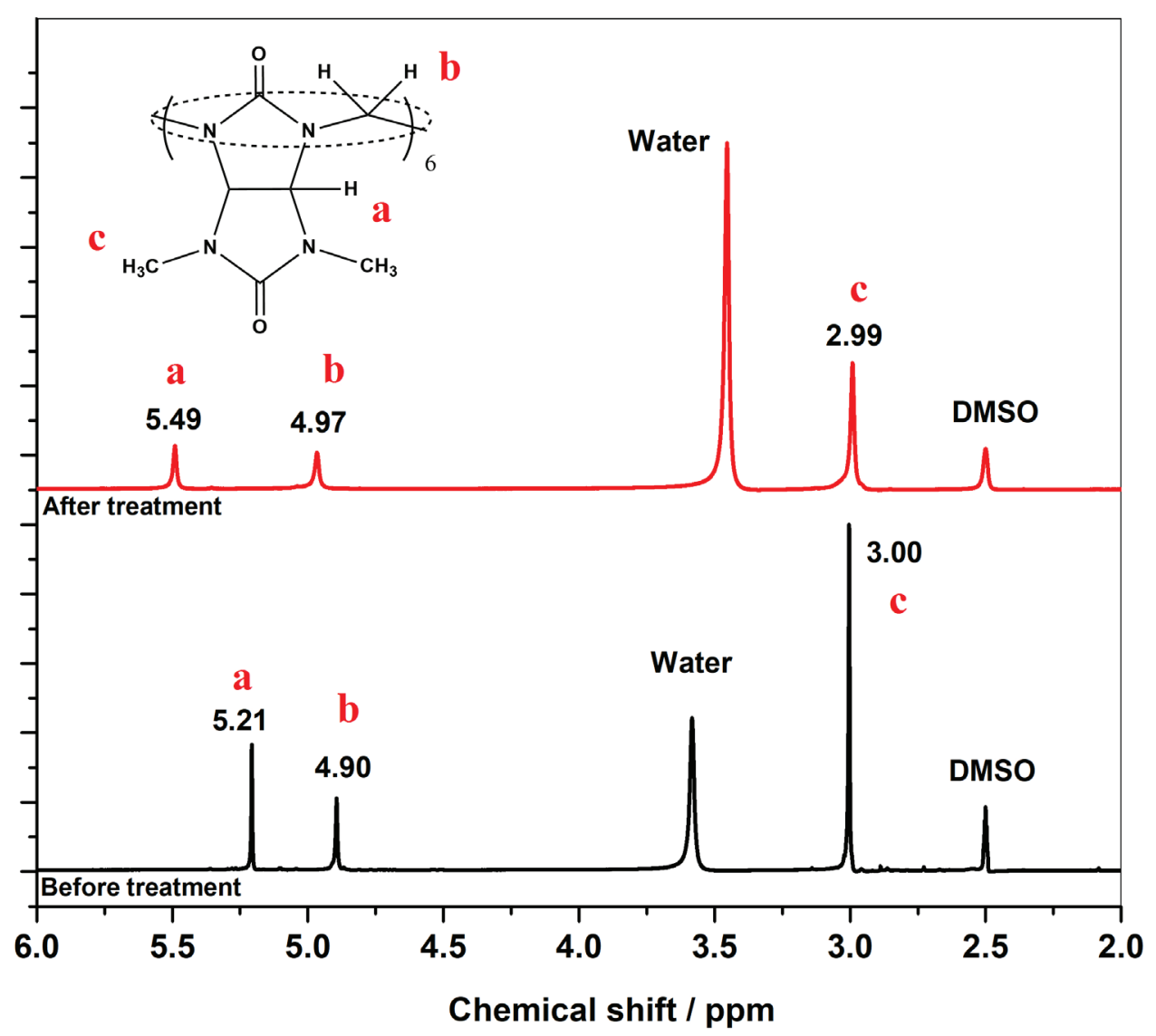

Figure 4. MeBU[6] ${ }^{1} \mathrm{H}$ NMR spectra $\left(500 \mathrm{MHz}, \mathrm{DMSO}-d_{6}\right)$ before and after the reaction of perchlorate ions with hydriodic acid in excess.

$\mathrm{H}^{+}\left(\mathrm{ClO}_{4}^{-} @ \mathrm{MeBU}[6]\right){ }^{1} \mathrm{H}$ NMR spectrum shows three peaks at 5.21, 4.90 and $3.00 \mathrm{ppm}$ assigned to methynic $(-\mathrm{CH})$, methylenic $\left(-\mathrm{CH}_{2}\right)$ and methylic $\left(-\mathrm{CH}_{3}\right)$ hydrogens, respectively. After the treatment with hydriodic acid (in excess), the peaks at 5.21 and $4.90 \mathrm{ppm}$ disappear completely from the spectrum and two new signals show up at 5.49 and $4.97 \mathrm{ppm}$ (see Figure 4). These latter peaks are assigned to methynic $(-\mathrm{CH})$ and methylenic $\left(-\mathrm{CH}_{2}\right)$ hydrogens of $\mathrm{H}^{+}\left(\mathrm{I}^{-} @ \mathrm{MeBU}[6]\right)$, respectively.

Chloride ions are also produced alongside iodide ions, as shown in equation 1 , but the huge excess of hydriodic acid and higher association constants of iodide $\left(10^{3}\right.$ times higher than with chloride) with MeBU[6], led solely to the formation of $\mathrm{H}^{+}\left(\mathrm{I}^{-} @ \mathrm{MeBU}[6]\right){ }^{.}$Following the procedure described elsewhere, ${ }^{5}$ one can easily obtain anion-free MeBU[6] from the reaction of $\mathrm{H}^{+}\left(\mathrm{I}^{-} @ \mathrm{MeBU}[6]\right)$ with hydrogen peroxide.

\section{Conclusions}

To conclude, MeBU[6] synthesis yields may be improved by using large anions such as $\mathrm{ClO}_{4}^{-}$ions in the form of their respective acids. We could obtain up to $70 \%$ yields in less than $48 \mathrm{~h}$, with perchlorate, and this is much more advantageous than other methods. These ions act better as templates once they lead to higher methylene bridge dihedral angles in the cyclic structures and a higher cavity filling. Oxidizing anions will act the opposite way, since they will produce more by-products instead of MeBU[6].

\section{Supplementary Information}

Supplementary information (computational data and infrared, ${ }^{1} \mathrm{H}$ NMR and mass spectra) is available free of charge at http://jbcs.sbq.org.br as PDF file.

\section{Acknowledgments}

The authors thank the São Paulo Research Foundation (FAPESP, grants No. 2016/12666-1 and 2017/19595-5) and Brazilian National Research Council (CNPq, grants No. 457264/2014-4, 134552/2015-6 and 176793/2017-5) for financial support. The authors also thank Prof Richard I. Walton and Dr Guy Clarkson, both from University of Warwick (United Kingdom), for their valuable contribution to this work. 


\section{References}

1. Cicolani, R. S.; Demets, G. J. F.; Quim. Nova 2018, 41, 912.

2. Lizal, T.; Sindelar, V.; Isr. J. Chem. 2017, 58, 326.

3. Cova, T. F.; Nunes, S. C.; Valente, A. J.; Melo, T. M. P.; Pais, A. A.; J. Mol. Liq. 2017, 242, 640.

4. Svec, J.; Necas, M.; Sindelar, V.; Angew. Chem., Int. Ed. 2010, 49, 2378.

5. Svec, J.; Dusek, M.; Fejfarova, K.; Stacko, P.; Klán, P.; Kaifer, A. E.; Li, W.; Hudeckova, E.; Sindelar, V.; Chem. - Eur. J. 2011, 17, 5605 .

6. Fiala, T.; Ludvíková, L.; Babiak, M.; Necas, M.; Kulhánek, P.; Klán, P.; Sindelar, V.; J. Am. Chem. Soc. 2017, 139, 2597.

7. Cicolani, R. S.; de Oliveira-Filho, A. G. S.; Batista, A. P. L.; Demets, G. J.-F.; New J. Chem. 2020, 44, 2697.

8. Lang, C.; Mohite, A.; Deng, X.; Yang, F.; Dong, Z.; Xu, J.; Liu, J.; Keinan, E.; Reany, O.; Chem. Commun. 2017, 53, 7557.

9. Cicolani, R. S.; Job, A. E.; Tonin, F. G.; Correia, H. D.; Demets, G. J.-F.; Therm. Anal. Calorim. 2018, 136, 1195.

10. Correia, H. D.; Cicolani, R. S.; Moral, R. F.; Demets, G. J.-F.; Synthesis 2016, 48, 210.

11. Anderson, S.; Anderson, H. L.; Sanders, J. K. M.; Acc. Chem. Res. 1993, 26, 469.
12. Centelles, V. M.; Pandey, M. D.; Burguete, M. I.; Luis, S. V.; Chem. Rev. 2015, 115, 8736.

13. Kaabel, S.; Aav, R.; Isr. J. Chem. 2017, 58, 296.

14. Toman, P.; Vanura, P.; Acta Chim. Slov. 2011, 58, 846.

15. Toman, P.; Makrlík, E.; Vanura, P.; Monatsh. Chem. 2011, 142, 881.

16. Toman, P.; Vanura, P.; Acta Chim. Slov. 2013, 60, 174.

17. Spartan, version 14; Wavefunction Inc., Irvine, USA, 2014.

18. Becke, A. D.; Phys. Rev. A 1988, 38, 3098.

19. Lee, C.; Yang, W.; Parr, R. G.; Phys. Rev. B 1988, 37, 785.

20. Miehlich, B.; Savin, A.; Stoll, H.; Preuss, H.; Chem. Phys. Lett. 1989, 157, 200.

21. Stern, S. A.; Mullhaupt, J. T.; Kay, W. B.; Chem. Rev. 1960, 60, 185.

22. Smith, G. F.; Analyst 1955, 80, 16.

23. Marcus, Y.; Hefter, G.; Pang, T.-S.; J. Chem. Soc., Faraday Trans. 1994, 90, 1899.

24. Mecozzi, S.; Rebek Jr., J.; Chem. - Eur. J. 1998, 4, 1016.

25. Hong, C. C.; Rapson, W. H.; Can. J. Chem. 1968, 46, 2061.

Submitted: February 14, 2020

Published online: April 23, 2020 